\title{
Educação popular e movimentos sociais na América Latina: o desafio da participação cidadã
}

\author{
Popular education and social movements in Latin America: the \\ challenge of citizen participation
}

Jaime José Zitkoski*

Universidade Federal do Rio Grande do Sul

Resumo O estudo analisa, através de pesquisa bibliográfica, os desafios que hoje se colocam aos Movimentos Sociais Populares na América Latina para construirmos novas formas de organização das lutas sociais. No atual contexto, um dos maiores desafios para os povos latino-americanos é resistir frente à intensa desmobilização das pautas sociais imposta pela globalização hegemônica. Despontam com mais força as pautas conservadoras, que revelam os interesses do poder econômico das instituições financeiras, aliando a mídia com o mercado, impondo uma agenda política em plano internacional. Mas nenhum poder, por mais fortemente estruturado que seja, é absoluto. Assim, o objetivo do artigo é evidenciar que o atual momento da América Latina é importante pelas experiências políticas que estão apresentando alternativas de democracia participativa e, igualmente, na produção da vida via outras economias.

PALAVRAS-CHAVE: Educação popular; Movimentos sociais; América Latina.

Abstract The paper examines, through bibliographical research, the challenges currently placed to the Popular Social Movements in Latin America that intend to organize new forms of social struggle. In the current context, one of the biggest challenges for the Latin American people is resist against the intense demobilization of social agenda imposed by hegemonic globalization. Conservative forces emerge more strongly, revealing the interests of financial institutions economic power, combining media and market, and imposing an international political agenda. But, no power is absolute, regardless how strong its structure may be. Thus, the objective of the article is to show that the current situation in Latin America is important for its political experiences, which present alternative of participatory democracy and, also in the production of life via alternative economies.

KEYWORDS: Popular education; Social movements; Latin America. 


\section{Introdução}

A relação entre Educação Popular (EP) e Movimentos Sociais na América Latina possibilita discutir propostas inovadoras na luta política das classes populares para se articularem em redes contra-hegemônicas ao capital hoje cada vez mais globalizado (SADER, 2009). Ou seja, é necessário buscar alternativas nas formas de organização dos movimentos sociais populares em um contexto sociocultural e político fortemente marcado pelo retorno das pautas conservadoras, que alimentam o ódio e a intolerância ao diferente.

A perversidade do capitalismo na sua forma dos mercados globalizados, que na vertente neoliberal aprofunda a competição e a exclusão social, requer que as sociedades e os povos da periferia do sistema liderem a busca de alternativas (GENTILI, 2001). Isso é decorrente pois, a cada ano que passa, a crise do capitalismo se mostra mais profunda e, para perpetuar sua lógica, exige mais sacrifícios humanos, sociais e da própria natureza (meio ambiente). Sendo assim, as rupturas dessa lógica perversa e injusta jamais virão do centro do sistema.

Diante dessa realidade, é uma questão de coerência entre visão teórica e ação prática que, frente ao atual contexto da globalização neoliberal, os movimentos sociais populares em suas lutas concretas defendam uma posição firme em prol de um projeto social transformador (emancipatório), a partir da cultura de cada sociedade concreta (SADER, 2009). Pois, os desafios para superar os modelos hegemônicos de organização política e estruturação dos mercados, da lógica puramente econômica na reprodução material da vida, requerem a reinvenção da política e da economia a partir das margens da sociedade. Nesse sentido, faz-se necessário lançarmos algumas perguntas: de onde hoje pode vir o novo na sociedade e que tenha capacidade de oferecer novos impulsos para a história da humanidade? Qual o horizonte possível na busca de superação dos dilemas que enfrentamos na política, na economia e na produção da cultura contemporânea?

\section{Educação popular e movimentos sociais na América Latina: as lutas históricas por transformação social}

A razão fundamental para discutirmos essa temática, que relaciona os Movimentos Sociais e a Educação Popular, reside na concepção ética e política de educação frente à realidade latino-americana. Uma educação comprometida com o processo de libertação de tudo o que oprime os povos da América Latina, que historicamente sofreram um brutal processo de dominação que deixou marcas profundas na sociedade, com enormes dificuldades socioeconômicas reveladas na exclusão social e um continente marcado pelo abismo entre ricos e pobres.

O trabalho mais orgânico da Educação Popular emergiu na América Latina no início da década de 1960 na modalidade de movimentos populares (de intelectuais, das pastorais sociais, estudantes universitários, setores políticos progressistas), desenvolvendo um trabalho político-pedagógico de ação cultural que desembocou no movimento social, através das inúmeras práticas de cultura e educação carregadas de valores e símbolos. 
Dessa forma, a concepção ético-política da EP, enquanto proposta de mobilização popular em prol das transformações sociais, se caracteriza, então, por estratégias bem claras e definidas de organização da sociedade civil (ZITKOSKI, 2000). Tal processo ocorreu através de várias formas de ações políticas que, ao respeitar a cultura popular, visaram, sobretudo, desenvolver a criticidade e a organização política das classes populares a partir da participação democrática.

A EP consiste, então, na identidade de um movimento que parte da organização das classes populares em seus desafios concretos de cada realidade específica. Não é, portanto, um nível nem uma modalidade de trabalho pedagógico interno ao sistema de ensino, mas a necessidade dos movimentos sociais estabelecerem sua prática pedagógica e se organizarem com ideias e estratégias de luta contra-hegemônica. Segundo Brandão, as principais características da EP são:

Uma educação que busca compromissos com as classes populares;
movimentos de educação popular em setores que realizam trabalhos
com o povo através da Igreja, agências de saúde, comunicação social,
mobilização popular; e o movimento social como um lugar de re-
alização da Educação Popular, sendo um movimento ou uma ação
pedagógica. (BRANDÂO, 1985, p. 148).

Nessa maneira de conceber, a EP desponta uma estratégia militante junto às classes populares, sem querer institucionalizar o seu trabalho político. Esse saber construído pelo povo tem produzido no Brasil formas de articulação de redes de movimentos sociais voltados para o trabalho político ou social numa perspectiva emancipatória, a exemplo dos Movimentos Populares, Movimento Estudantil e, mais recentemente, do Orçamento Participativo e da Escola Cidadã. Por resistir a se tornar um exercício pedagógico fechado e/ou institucionalizado, a EP se torna a possibilidade prática da crítica dos sistemas hegemônicos e institucionalmente estruturados numa lógica do controle social.

Outro aspecto fundamental, que também caracteriza a EP, é que ela não se realiza apenas por um momento de crítica e subversão da educação elitista e opressora, mas pela busca do espaço de militantes e líderes populares, que na maioria dos casos não são educadores de carreira, em construir socialmente novas alternativas de organização da vida em sociedade. Esse trabalho orienta-se no horizonte da organização das classes populares de forma consciente, politizada e culturalmente original, porque vertida desde a realidade da vida das pessoas via práxis social das comunidades populares.

\footnotetext{
Deve-se ressaltar que a identidade da EP está atrelada à opção pelo fortalecimento das organizações e movimentos gestados pelos setores populares, trabalhando coletivamente para o desenvolvimento de condições subjetivas e objetivas que possibilitem a construção do sujeito capaz de alcançar sua emancipação. Para a EP, a organização é ao mesmo tempo um objetivo e um fim. (GOLSALVES, 1998, p. 214).
}

A própria concepção de educação não formal, que estava na origem da $\mathrm{EP}$ nos anos de 1960 (BRANDÃO, 1995), discutindo uma formação mais ampla do ser humano (para além dos processos formais) é também uma característica marcante 
desse movimento pedagógico inovador. É uma concepção de educação que busca construir-se na relação direta com propostas de intervenção política e cultural na sociedade, lideradas pelas classes populares. O homem aprende desde as suas origens ,e a relação da ideia de aprendizagem à de conscientização passa a ser o fundamento da EP, pois o processo de coproduzir o saber a partir da lógica da própria cultura é pedagogicamente mais importante do que o produto de tal saber. Ou seja, a práxis da transformação social desde uma perspectiva de Marx aponta que:

[...] o importante não é compreender o que as pessoas produzem materialmente, mas como socialmente se organizam para produzir, a mesma ideia vale como base do imaginário da educação popular: não importa o que as pessoas sabem, mas como elas vivem a experiência coletiva de produzir o que sabem, e aquilo em que elas se transformaram ao experimentar o poder de criar tal experiência do que o saber é um produto. (BRANDÃO, 1985, p 157).

Dentro desse caminho aberto, solidário, esperançoso e utópico que caracteriza a EP na América Latina enquanto projeto de transformação social, podemos dizer que um dos princípios originários desse paradigma educacional é a criação de uma nova epistemologia.

Uma epistemologia baseada no profundo respeito ao senso comum que trazem os setores populares em sua prática cotidiana, problematizando esse senso comum, tratando de descobrir [...] a teoria ainda não conhecida pelo povo e problematizá-la, incorporando-lhe um raciocínio mais rigoroso, científico e unitário. (GADOTTI; TORRES, 1992, p. 8).

Os fundamentos dessa nova epistemologia visam aplicar a lógica dialética ao mundo existencial vivido pelo povo latino-americano. Nesse sentido, Freire (1994) recria o pensamento dialético, tanto da tradição idealista quanto da tradição marxista. A dialética em Freire segue um princípio inovador que é a articulação entre o diálogo crítico problematizador e a práxis social transformadora. Dialética para Freire, em síntese, é a constante tensão entre consciência e mundo, subjetividade e objetividade, visando, sobretudo, a humanização do mundo que passa pela humanização da cultura, das estruturas sociais, da política, da economia, enfim, da vida em sociedade.

Nessa perspectiva, o ponto de partida da EP é, como inúmeras vezes nos reforça Paulo Freire, a cultura, o saber, o mundo vivido do povo, não apenas para redizê-lo, mas para problematizar seus fundamentos, suas bases de sustentação. Esse caminho a ser trilhado requer que o povo alcance uma compreensão crítica de sua própria existência e consiga pensar o mundo em que vive e projetá-lo de outra maneira que não a simples repetição de seu cotidiano.

Não vejo como a educação popular, não importa onde e quando, pudesse ter prescindido ou possa prescindir do esforço crítico a envolver educadores e educadoras, de um lado, e educandos, de outro, na busca da razão de ser dos fatos. Em outras palavras, centrando-se a educação popular na produção cooperativada, na atividade sindical, na mobilização e na organização da comunidade para a assunção por ela da educação de seus filhos e filhas através das escolas comunitárias [...] qualquer que seja a hipótese, não é possível descartar o processo gnosiológico. (FREIRE, 1994, p. 132). 
Buscar a razão de ser da realidade é buscar o logos, a compreensão crítica, o desvelamento do que seja o mais verdadeiro na compreensão dos processos históricosociais que produzem a realidade. Para tanto, educadores e educandos devem começar pela pergunta do porquê dos fatos que os cercam, o porquê da vida que levam, de seu cotidiano social, enfim, das realidades que constituem suas vidas (FREIRE, 1996). Da mesma forma, devem se perguntar sobre o "para quê" da educação, para quem, contra quem, a favor de quem e a favor de quê. É no exercício da criticidade que a EP realiza com vigor o processo gnosiológico (FREIRE, 2001), que deve fazer parte da própria essência da educação.

Mas o mero treinamento técnico, que hoje as elites buscam impor às camadas populares para reproduzir a lógica dominante, visa exatamente ao contrário da educação crítica, pois nega a problematização, a compreensão crítica e a própria cientificidade na apreensão do mundo existencial em que o educando vive. Assim, como se não bastasse o grande equívoco científico do tecnicismo aplicado no Brasil dos anos 70 , hoje a classe dominante, em articulação com suas estratégias de dominação política, pretende reeditar o antigo projeto de educação para este servir como mero treinamento às novas gerações de técnicos qualificados. O neotecnicismo tem por meta primeira o cumprimento de sua função político-ideológica, de servir como instrumento de formação dos profissionais qualificados para o atual sistema econômico que, por ser mais competitivo, exige um novo perfil de mão de obra (GENTILI; SILVA, 1995).

Além da sua base epistemológica original, a EP trabalha com uma concepção de política inovadora, através da qual se colocam, como questão primeira, as relações de poder no interior do sistema social. Ou seja, o questionamento crítico sobre o que é e quem tem poder nas sociedades atuais, o que significa exercer o poder, como esse poder é legitimado e que perspectivas e práticas deve exercer o poder popular para desenvolver uma sociedade emancipatória.

Problematizando estas questões, a EP concebe que não há educação neutra, apolítica, pois o conhecimento é perpassado por interesses sociais e os subsistemas de uma sociedade estão em estreita interdependência com a totalidade do sistema social. Portanto,

\begin{abstract}
a educação popular, na qualidade de política, tem por objetivo caracterizar a situação das classes populares na América Latina, submetidas à hegemonia (posta ou adaptada) das classes dominantes, frações de classes, grupos de interesses e poder e grupos culturais que lhes são estranhos. Neste processo [...]a tarefa educativa consiste em propiciar uma reflexão crítica das condições em que se cria essa hegemonia e, por sua vez, em alterar essa hegemonia propondo uma nova ordem social, uma nova cultura política, um novo estilo de relação educativa, enfim, um novo projeto social. (GADOTTI; TORRES, 1992, p.9).
\end{abstract}

Esta é a meta para a qual converge a EP enquanto utopia latino-americana que poderá recriar nossa história a partir da luta contra-hegemônica das classes populares (GADOTTI, 1994). O sentido e a coerência política do trabalho concreto da EP estão nessa radicalidade da proposta de transformação social. Não há como se con- 
tentar apenas com remendos e/ou reformas paliativas - que não modificam as bases do atual sistema social essencialmente desumano, opressor e alienante. Aos oprimidos não resta outro caminho histórico senão a luta para se libertarem de tudo aquilo que os proíbem de ser, ou seja, o caminho concreto de superação das causas da opressão - que são os próprios sistemas políticos, econômicos, culturais e sociais hoje vigentes. Tal superação só poderá ocorrer através do embate político liderado pelos setores oprimidos, no qual a hegemonia dominante é questionada, desarticulada e aos poucos substituída pela construção de um novo poder - que vem da união dos fracos, mas torna-se mais forte que o poder dos poderosos do mundo.

Para o êxito da luta, a consciência ética e a consciência política dos lutadores têm importância decisiva. A tecnologia é suplantada às vezes pela inventividade do mais fraco, possuidor, porém, de uma fortaleza que faz falta ao poderoso: a sua convicção ética e histórica de que sua briga é legítima. (FREIRE, 1994, p. 172).

Nessa luta, a EP inserida em diferentes espaços do quotidiano da vida das classes populares (Movimentos Sociais, Escola Pública, Economia Solidária, entre outros) desponta nas últimas décadas como um processo fecundo e de grande potencial na formação cultural e política das sociedades latino-americanas. Pois sua efetiva presença articula projetos a partir dos seguintes eixos de ação social: educação para a cidadania, participação social, organização dos setores populares e ampliação dos direitos através de novas conquistas.

Assim, no bojo dos processos emancipatórios - que visam a construir um novo projeto de sociedade - os Movimentos Populares, certamente, não dependem somente dos processos pedagógicos e/ou educativos (porque há outras instâncias do embate político, das estratégias mais imediatas que dão corpo e existência aos Movimentos Sociais). Mas, por outro lado, tais movimentos sociais não têm muito tempo de vida se descuidarem do papel formativo e conscientizador das dimensões pedagógicas e educativas, quanto menos teriam fôlego para romper a ordem dominante e instituir um novo projeto social sem o cuidado com a formação de lideranças e de uma nova cultura enquanto caminho para o exercício da cidadania e da vida democrática em sociedade.

O valor da dimensão educativa e/ou pedagógica na vida dos movimentos sociais reside em que a EP é a forma de educar o povo, tendo como princípio maior a própria realidade. É a educação que pode promover a resistência contra a dominação e desencadear um processo de emancipação social através da luta coletiva das classes populares. E, por isso mesmo dificilmente irão ocorrer avanços significativos nas esferas política, econômica e social sem o desenvolvimento cultural dos cidadãos através de um processo político-educativo realmente comprometido com as transformações sociais.

Enquanto intencionalidade política, além de defender uma sociedade democrática, a EP trabalha em favor da superação concreta das questões econômicas opressoras, tais como: a concentração da riqueza e da terra, da exclusão social, da miséria degradante e desumana, da falta de moradia e trabalho, da exclusão dos pobres ao direito à saúde, educação e alimentação digna. 


\section{Educação popular e participação cidadã: algumas experiên- cias que evidenciam o potencial de reinvenção da democra- cia}

A seguir buscarei analisar algumas experiências que despontam no contexto da década de 90 e início dos anos 2000, em um cenário de ampliação da democracia e de reinvenção dos espaços de construção da cidadania a partir da participação popular (DEMO, 2001). A EP busca se reinventar nas linhas de atuação teórico-metodológica e está conectada com as transformações que ocorrem a partir do novo ciclo da globalização em curso. Nessa direção, pretendo discutir a temática dos Movimentos Sociais, da metodologia da organização e participação popular, a democracia e exercício do poder e as novas formas de conceber políticas públicas para a educação na cidade.

\section{Educação popular e movimentos sociais: uma pedagogia da participa- ção}

No período de mais de quatro décadas de experiências inovadoras no propósito de organizar e qualificar os Movimentos Sociais, a EP tem acumulado experiências e metodologias de trabalho político-pedagógico que revelam a riqueza e sabedoria das classes populares em diálogo com os saberes acadêmicos.

A partir do desafio de se organizar para ter mais poder de luta por direitos sociais e na busca de construir um novo projeto de sociedade, tem se destacado, por exemplo, em plena época da ditadura militar no Brasil, o Método Ver-Julgar-Agir. É um método que esteve muito presente nas CEBs e hoje ainda é fecundo nas Pastorais Sociais.

Outra experiência metodológica fecunda da EP em toda a América Latina está relacionada à Pesquisa Participante, na qual autores como Brandão, Paulo Freire e Fals Borda trazem propostas concretas de uma metodologia que busca a síntese do saber popular com os saberes acadêmicos. A pesquisa participante é um caminho fecundo hoje para desenvolvermos um conhecimento comprometido com a vida e a transformação social em favor dos povos oprimidos e negados em sua cultura e nos saberes da experiência histórica.

Portanto, para a EP e os Movimentos Sociais, o desafio maior é organizar as classes populares articulando as diferentes iniciativas dos Movimentos Sociais em seus acúmulos históricos na busca de construir uma rede dos Movimentos Sociais alcançando, assim, maior amplitude e abrangência de mobilização da sociedade. É nessa direção que a proposta de Freire é categórica ao definir que se faz necessário a "união dos diferentes" para empoderar-se na luta contra os antagônicos. Nessa perspectiva, Freire coloca a importância do sonho e da esperança na construção de uma pedagogia da luta política. Ou seja:

O sonho pela humanização, cuja concretização é sempre processo, e sempre devir, passa pela ruptura das amarras reais, concretas, de ordem econômica, política, social, ideológica, etc. que nos estão condenando à desumanização. O sonho é assim uma exigência, ou uma 
condição que se vem fazendo permanente na história que fazemos e que nos faz e re-faz. (FREIRE,1994, p. 99).

Sem o sonho e a esperança não conseguimos mobilizar a nossa luta. Mas sem a luta a esperança também se perde na história. Por tal razão é que aos Movimentos Sociais é fundamental a organização para ampliar as conquistas das classes populares.

\section{A coerência teórico-metodológica no trabalho popular}

O referencial teórico da EP articula o pensamento dialético - buscando construir uma pedagogia da práxis tencionando sempre teoria-prática ${ }^{1}$ - com o pensamento fenomenológico de vertente existencialista. Nessa perspectiva é que emerge a pesquisa participante como um referencial teórico-metodológico inovador. A realidade social, cultural e política dos povos latino-americanos é o ponto de partida da EP na busca de potencializar a organização dos Movimentos Sociais progressistas.

Um exemplo prático desse caminho metodológico é a pesquisa dos Temas Geradores, que está bem delineada por Freire (1993), no terceiro capítulo de sua Pedagogia do oprimido. Outra construção fecunda é a pesquisa socioantropológica nos projetos da Escola Cidadã, que desponta nos anos 90 com as administrações populares na gestão de cidades importantes no Brasil.

O aspecto inédito dessas propostas metodológicas está na coerência em propor um caminho interdisciplinar na construção de saberes necessários para a humanização dos oprimidos (ZITKOSKI, 2006) e praticar o diálogo entre os diferentes núcleos/ethos culturais na perspectiva da elaboração de uma ciência biófila. Educação, nessa perspectiva, não significa apenas escola, saber formal, instrução, mas formação de um novo ser humano que, ao mesmo tempo, possa vivenciar novas práticas sociais, educando-se na participação cidadã em diferentes espaços de vida em sociedade para construir uma cultura crítico-humanizadora de afirmação de uma nova humanidade.

\section{O empoderamento das classes populares via a organização em projetos de economia solidária}

Nas quase cinco décadas de práticas de EP e organização das lutas e afirmação de conquistas pelos movimentos populares, ocorreu um acúmulo de experiências inovadoras na forma de construir o poder das classes populares. Mesmo a partir das experiências das administrações populares no Brasil, pelo menos no âmbito das administrações municipais, foram sendo construídas relações mais democráticas entre Estado e Sociedade Civil e surgiram alternativas criativas na perspectiva da democracia participativa e participação popular, tais como: Orçamento Participativo, Economia Solidária, Políticas Públicas voltadas para a inclusão social, Fórum Social Mundial (FSM), entre outras.

As iniciativas acima mostram que é possível articular as experiências de organização local com movimentos de âmbito nacional e internacional a partir da organização em redes colaborativas. Acima de tudo, as experiências do FSM organizadas desde 2001, a partir de Porto Alegre/RS, convergiram para o desafio de articular 
lutas populares a nível global na busca de resistência e construção de alternativas ao modelo da política neoliberal (SANTOS, 2008) e na forma de produzir a vida com mais dignidade.

Nessa direção, destacamos as ricas experiências de economia solidária no Brasil e América Latina, que tiveram início ainda nos anos 80. Despontaram inúmeros projetos de Economia Solidária, muitas vezes apoiados pelas "pastorais sociais" das Igrejas Cristãs, mas também fortemente articulados a partir dos movimentos sociais populares. O principal objetivo da Economia Solidária é a organização popular e a busca da autonomia e empoderamento das pessoas mais humildes, que mais sofrem com o desemprego, a fome, enfim, com a falta de uma renda digna para viver. Segundo Singer (2008), o grande potencial da Economia solidária, através da organização da sociedade em redes de colaboração desde a produção até a distribuições de bens materiais e sociais, poder vir a ser no futuro o caminho mais curto para chegarmos ao socialismo.

Nessa mesma direção, Cunha (2011) destaca que "qualquer teorização económica pós-capitalista não vai poder ignorar que a riqueza tem que ser gerada e distribuída de forma a aumentar o conforto e diminuir os sacrifícios de todas as pessoas. Não basta redistribuir; é preciso promover o bem-viver e o bem-estar de todas e todos" (p. 93). Portanto, além do potencial político organizativo da ES, podemos destacar seu papel humanizador nas relações sociais e na busca da dignidade humana.

\section{Educação popular e escola pública popular}

A partir das experiências das administrações populares de 1989 em diante, e, principalmente, com o desafio pessoal de Paulo Freire como secretário de educação na cidade de São Paulo no governo Luiza Erundina, teve início, no Brasil, um movimento para construir alternativas pedagógicas no interior das redes públicas de escolas a partir dos princípios e da intencionalidade da EP. O Movimento que passou a se chamar de Escola Cidadã teve origem em São Paulo com a administração de Paulo Freire (GADOTTI, 1995). A tese freiriana parte da realidade de que, se as classes populares são quem frequenta majoritariamente as escolas públicas, por que estas escolas funcionam na lógica das elites? Elas não poderiam ser reorganizadas para se aproximarem da lógica cultural, dos anseios e saberes do povo e dos interesses das classes populares?

Eis a origem do debate para a busca de reinventar a escola pública a partir das experiências e do referencial teórico-metodológico da EP. Podemos citar algumas cidades que buscaram concretizar o projeto Escola Cidadã: São Paulo/SP, Porto Alegre/RS, Caxias do Sul/RS, Alvorada/RS, Chapecó/SC, Cuiabá/MT, Gravataí/RS, entre outras. Sobre a experiência de Porto Alegre, têm diferentes registros e livros organizados, dentre os quais destacamos o livro organizado por Carlos Rodrigues Brandão, intitulado: A Educação Popular na Escola Cidadã (2002).

Mas, atualmente, estão em curso inúmeras experiências que buscam reinventar a Escola Pública a partir da participação dos cidadãos nos diferentes projetos, principalmente diante do desencanto da escola enquanto instituição. Esse caminho é 
necessário para conferir um novo sentido para a construção de uma sociedade democrática efetiva.

\section{Cidades educadoras e participação cidadã}

A concepção de Cidade Educadora está diretamente vinculada à participação popular nos rumos da cidade, pois a partir desta é possível delinear a formação de uma cidadania emancipatória na busca de construir uma sociedade fundada na democracia real e na justiça social.

O conceito Cidade Educadora demarca como princípio que o poder público municipal e a sociedade civil organizada, de forma articulada, precisam exercer sua função educadora na busca da construção de uma nova cultura política, que se fundamentam na solidariedade entre pessoas, grupos sociais e instituições para enfrentar a lógica individualista e excludente do neoliberalismo em curso.

Cidade Educadora não se trata de uma ação educadora qualquer, mas de um projeto educativo vinculado aos processos democráticos e participativos, que estão emergindo no Brasil e América Latina a partir dos movimentos sociais progressistas. É um projeto educativo que assimila, mas supera os princípios e conceitos da educação escolar. Mais do que isso, a Cidade Educadora educa a própria escola e é educada por ela, que passa a assumir, nessa perspectiva, um papel mais amplo na superação da violência e exclusão social (GADOTTI; PADILHA: CABEZUDO, 2004).

Não basta a educação escolar trabalhar em prol da formação de uma cultura cidadã, embora isso seja importante enquanto articulação da vida social na comunidade. Como agentes sociais e políticos, comprometidos com um projeto social emancipatório, precisamos ampliar a abrangência de nossas ações rumo à cidadania emancipatória.

Nessa perspectiva, o projeto das Cidades Educadoras se articula com o movimento da Escola Cidadã, mas quer ir além da escola. É um desafio mais articulado e interdisciplinar entre as diferentes áreas de atuação do poder local e articulação da participação popular a nível de município. Segundo Gadotti et al (2004), o papel das políticas públicas no contexto do movimento Cidades Educadoras é contribuir para criar as condições que viabilizem uma nova cidadania, através da socialização das informações, da discussão das prioridades para os diferentes setores sociais, da transparência dos recursos públicos, gerando, assim, uma nova mentalidade e uma nova cultura em relação ao caráter público do espaço da cidade.

\section{Considerações finais}

Considerando o conjunto da reflexão sobre os projetos e experiências de participação popular e empedramento da cidadania, coloca-se a questão: Como articular as experiências locais com o poder regional - nacional e internacional? Como os movimentos sociais populares poderão se fortalecer na luta por uma sociedade justa e democrática na América Latina no atual contexto da globalização neoliberal? 
Não há receitas prontas de como fazer história ou organizar a luta popular. Mas uma questão fundamental está colocada para as classes populares, a saber: construir a sabedoria política na forma de organizar a luta a partir da "união dos diferentes para lutar contra os antagônicos" (FREIRE,1994). Essa articulação entre os movimentos sociais exige diálogo, humildade e uma educação da esperança. Pois não podemos cair no imediatismo e nem reproduzir a lógica da competição entre os diferentes. Isso só fortalece o poder das classes dominantes que vem se articulando em redes há muito tempo.

Nesse sentido, a utopia da EP e dos movimentos sociais progressistas tornase cada vez mais atual e necessária. Aliás, é o que diz o lema do Fórum Social Mundial: Outro mundo é possível e necessário.

A EP vem construindo diferentes processos de organização das classes populares na perspectiva da reinvenção do poder. Contudo, os desafios colocados no atual contexto dos países latino-americanos, com governos ditos de esquerda por um lado, mas com uma herança histórica de um Estado burguês, nos colocam à prova diante da necessária construção de um projeto social emanciatório. Nesse contexto, a EP jamais pode esquecer suas raízes históricas e precisa reinventar seu caminho junto com os oprimidos. Mas, além de estar junto com o povo, é fundamental se articularmos com todos aqueles que praticam a verdadeira solidariedade na busca da transformação dessa sociedade injusta e opressora.

\section{Referências}

BRANDÃO, C. R. A educação como cultura. São Paulo: Brasiliense, 1985.

Em campo aberto: escrito sobre a cultura e a educação popular. São Paulo: Cortez, 1995.

A Educação popular na escola cidadã. Petrópolis: Vozes, 2002.

CUNHA, T. (Org.) Ensaios Pela democracia, Justiça, Dignidade e Bem-Viver. Edições Afrontamento: Porto, 2011.

DEMO, P. Conhecimento e Aprendizagem: atualidade de Paulo Freire. In: PAULO FREIRE e a Agenda da Educação Latino-Americana no Séc. XXI. Buenos Aires: CLACSO, 2001.

FREIRE, P. Pedagogia do Oprimido. São Paulo: Paz e Terra, 1993.

Pedagogia da Esperança. São Paulo: Paz e Terra, 1994.

Pedagogia da Autonomia. São Paulo: Paz e Terra, 1996.

Pedagogia da Indignação. São Paulo: Ed. UNESP, 2001.

GADOTTI, M.; FREIRE, P.; TORRES, C. A. Estado e Educação Popular. São Paulo: Papirus, 1992.

(Org.) Educação Popular: Utopia Latino-americana. São Paulo: Cortez, 1994.

. (Org.). Paulo Freire: uma biobibliografia. São Paulo: Cortez, 1995.

FREIRE, P.; PADILHA, P.; CABEZUDO, A. (Orgs.). Cidade Educadora: princípios e experiências. São Paulo: Cortez, 2004.

GENTILI, P. Pedagogia da Exclusão: crítica ao neoliberalismo em educação. Petrópolis: Vozes, 2001. 
GENTILI, P.; SILVA, T.T. (Orgs.). Neoliberalismo, Qualidade Total e Educação. Petrópolis: Vozes, 1995.

GOLSALVES, E. P. Educação Popular: entre a modernidade e a Pós-modernidade. In: Educação Popular. São Paulo: Loyola, 1998.

SADER, E. A nova toupeira: os caminhos da esquerda latino-americana. São Paulo: Boitempo, 2009.

SANTOS, B. S. O Futuro do Fórum Social Mundial. São Paulo: Ed. Cortez, 2008.

SINGER, P. Economia Solidária (Entrevista). In: Revista Estudos Avançados, vol. 22, n. 62: São Paulo, Cidade Universitária - USP, jan./abr. 2008.

ZITKOSKI, J. J. Horizontes da Refundamentação em Educação Popular: um diálogo entre Freire e Habermas. Frederico Westphalen: URI, 2000.

Paulo Freire \& a Educação. Belo Horizonte: Autêntica, 2006.

\section{Notas}

${ }^{1}$ Ver, por exemplo, o início do $3^{\circ}$ capítulo da Pedagogia do Oprimido de Paulo Freire.

* Professor doutor da Universidade Federal do Rio Grande do Sul, Porto Alegre, Rio Grande do Sul, Brasil.

\section{Correspondência}

Jaime José Zitkoski - Universidade Federal do Rio Grande do Sul, Faculdade de Educação. Avenida Paulo Gama s/n, Prédio 12201, sala 930. Redenção. CEP: 90046900. Porto Alegre, Rio Grande do Sul, Brasil.

E-mail:00086365@ufrgs.br

Recebido em 13 de novembro de 2015

Aprovado em 31 de outubro de 2016 